\title{
Anhedonia in Depressive Disorder: A Narrative Review
}

\author{
Jürgen De Fruyt ${ }^{a}$ Bernard Sabbe ${ }^{b, c}$ Koen Demyttenaere ${ }^{d}$ \\ a Department of Psychiatry, General Hospital Sint-Jan Brugge-Oostende AV, Bruges, Belgium; \\ b University Department of Psychiatry, Campus Psychiatric Hospital Duffel, Duffel, Belgium; \\ ${ }^{c}$ Collaborative Antwerp Psychiatric Research Institute, University of Antwerp, Wilrijk, Belgium; \\ ${ }^{\mathrm{d}} \mathrm{KU}$ Leuven, Faculty of Medicine, Department of Neurosciences, Psychiatry Research Group and \\ University Psychiatric Center KU Leuven, Campus Gasthuisberg, Leuven, Belgium
}

\section{Keywords}

Anhedonia $\cdot$ Pleasure · Depressive disorder · Major

depressive disorder

\begin{abstract}
Since the introduction of DSM-III anhedonia has become a core depressive criterion and is defined as the loss of interest or pleasure. Although the origin of the word goes back to the end of the 19th century and numerous anhedonic symptoms are described in classic texts on depression, this centrality in the diagnosis of depression is only recent. Anhedonia is best described as a symptom complex with unclear boundaries cutting across the tripartite model of the mind (affect, volition, and cognition). Popular concepts of anhedonia pertain to the pleasure cycle and positive affectivity. These concepts partially overlap and are often mixed up, but clearly stem from different theoretical backgrounds: the affective science of reward processing versus more general, dimensional modelling of affect. The former concept seems more suitable to understand anhedonic emotions, the latter more suitable to understand anhedonic mood or trait. This narrative review covers the history of "anhedonia," the different anhedonic phenomena, and psychopathological con-
\end{abstract}

(C) 2020 S. Karger AG, Basel

www.karger.com/psp

Karger cepts. An attempt is made to go beyond a merely descriptive psychopathology. Neurobiological and psychological insights shed a light on how symptoms are made and interconnected; these insights possibly call for a new psychopathological language.

(c) 2020 S. Karger AG, Basel

\section{Introduction}

The DSM-5 diagnosis of major depressive disorder (MDD) [1] depends upon the presence of at least 5 depressive symptoms that have been present during the same 2-week period and represent a change from previous functioning. At least one of these symptoms has to be either: (1) depressed mood or (2) loss of interest or pleasure. The compound feature of anhedonia as a loss of interest or pleasure, and its importance as a core depressive criterion goes back to DSM-III [2] and its predecessor, the Research Diagnostic Criteria (RDC) [3]. The authors of the RDC were very aware that many "depressed" patients did not endorse feelings of depression, sadness, or other types of dysphoric mood, but instead reported loss of interest and pleasure in everything. They added "per- 
vasive loss of interest or pleasure" to dysphoric mood as a MDD core criterion. By doing so, they wanted to avoid the diagnosis of depression being solely dependent on reports of dysphoric mood (Jean Endicott, pers. communication). In prior classification systems of depression, anhedonia was either not mentioned at all [4-6], limited to decreased sex interest only [7], or limited to loss of interest or decrease in sexual drive [8]; this contrasts with the importance of anhedonic symptoms in historical descriptions of major depression $[9,10]$.

The appearance of anhedonia as a core depressive feature in RDC and DSM-III $[2,3]$ coincided with the work of Donald Klein [11, 12] on the importance of anhedonia in endogenomorphic depression. Building upon his experience in drug addiction and the biological treatment of depression, Klein theorized 2 different pleasure mechanisms: consummatory (pleasures in biological drive reduction; for example, eating, sexual orgasm, and sleep), and appetitive (pleasures associated with pursuit, being able to go after things with interest). Two different types of depression were identified: a first group with only impairment of appetitive pleasure, and a second group with impairment of both appetitive and consummatory pleasure. This latter group was called endogenomorphic depression and was characterized by "a sharp, unreactive pervasive impairment of the capacity to experience pleasure or to respond affectively to the anticipation of pleasure."

Since Klein, new insights into anhedonia have come from many sources, for example, historiographical accounts [13-15], psychological theories of positive and negative affect [16], and the neuroscience of pleasure and anhedonia [17-19]. Clinical research has shown the importance of anhedonia (or positive affect as its counterpart) in, for example, the prediction of response and the subjective feeling of remission [20-23]. Reward sensitivity/learning (constructs related to anhedonia) has been proposed as a potential endophenotype for MDD [24, 25].

From a clinical and psychopathological viewpoint, however, many questions remain unanswered, with important questions being: how to assess anhedonia in a proper clinical way, and how to relate findings from psychological theories and basic neurosciences with clinical psychopathology? According to Berrios [15], "the understanding of anhedonia requires that the word, concept, and behaviour are investigated separately". This paper then presents a narrative overview of anhedonia in MDD: the historical origin of the word, the different behaviours described, the different concepts theorized, and finally how anhedonia as a word, behaviour, concept, and psychopathology could relate.

What We Talk about When We Talk about Anhedonia in Depression

\section{Anhedonia: The Word}

In 1896 the French psychologist Théodule Ribot coined the neologism "l'anhédonie" (the disappearance of pleasure) in analogy with "l'analgésie" (the absence of pain) [26]. He refers to the total loss of pleasure, both physical and psychic, in melancholia. Two case reports are provided showing loss of pleasure, affective response, emotional reactivity, and interest. Similar descriptions of anhedonic symptoms were made by Georges Dumas (a French physician/psychologist and pupil of Ribot) in his doctoral thesis on sadness and joy [27]. Dumas used "moral anaesthesia" (not anhedonia) as an umbrella term. Anhedonia survived, moral anaesthesia did not. American psychologist William James [28] adopted anhedonia in his textbook on the varieties of religious experience. James distinguishes anhedonia as one of the many kinds of pathological depression, joining "passive joylessness and dreariness, discouragement, dejection, lack of taste and zest," "incapacity for joyous feeling," "passive loss of appetite for all life's values." In 1922, the American psychiatrist Abraham Myerson devoted an entire lecture during the annual meeting of the American Psychiatric Association to the topic of anhedonia [29]. Myerson referred to Ribot and James but took a more psychobiological stance. He described anhedonia as a symptom complex that occurs in many mental diseases and different psychoneuroses: "a kind of organic anaesthesia," "a dropping out from consciousness of desire and satisfaction." Besides these latter 2 components, Myerson added disappearance of the feeling of energy and feelings of unreality. He also suggested a practical therapeutic approach: restoration of appetite, sleep, energy feeling, and preventive measures.

In contrast with this early conception of anhedonia, there was a general falling away of interest during the twentieth century. In a bibliometric search (PubMed search for "depression AND anhedonia"; last search performed on December 5, 2018), a first citation only appears in 1959 [30]. Publication activity remained scarce (a maximum of 7 citations/year) until the beginning of the 1990s. From then on, an increase is found reaching 271 citations in 2018. According to Snaith [31], the falling away of interest was influenced by the increasing focus on depressed mood. The resurgence of interest is then attributed to the publication of DSM-III [2], which positioned anhedonia as a core depressive symptom. 
Table 1. Anhedonic symptoms in psychiatric texts

Clinical Lectures on

Mental Diseases [32]
Loss of sense of wellbeing, of conscious enjoyment of anything, of volitional power, of spontaneity, paralysis of feeling (p. 24; first symptoms of melancholia) Want of affection, want of interest in and enjoyment of life (p. 24; simple melancholia) It begins in most patients as simple lowness of spirits, and lack of enjoyment in occupation and amusement, and loss of interest in life (p. 115; the inception of melancholia) A paralysis of the sense of wellbeing and the enjoyment of life, a difficulty in coming to decisions, a loss of mental energy, an intolerance of the usual work, if not an actual incapacity to do it well (p. 96; organic melancholia)

A Text-Book of Mental Diseases [33]

The patient exhibits a growing indifference to his former pursuits and pleasures: the ordinary duties of life and business become irksome and devoid of interest. Especially do all forms of mental exertion cause ennui and distaste, the attention cannot as formerly be directed without undue effort, and so reading becomes laborious and thought sluggish and monotonous. The environment fails to call up pleasurable associations, a dreariness and gloom pervade the outside world, since it is interpreted in terms of the predominant feeling. All aspects of object-consciousness alike indicate the negative state. There is a want of vigor in the representation of the environment, and feelings aroused thereby are at a low ebb (p. 143144 ; states of depression)

A universal gloom pervades his mind, and a distaste for all previous avocations and interests declares itself: exercise and all forms of recreation no longer appeal to him, and a dull uniform level of indifference is engendered towards the outside world. Life has lost its freshness. Nature presents him with no delights, and whatever there be of beauty or happiness or gaiety around, but serves to emphasize his gloom as he feels their want of kinship to his nature (p. 168; simple melancholia)

Manic-Depressive Insanity The patient's heart is heavy, nothing can permanently rouse his interest, nothing gives him pleasure. He and Paranoia [34] has no longer any humor or any religious feeling, he is unsatisfied with himself, has become indifferent to his relatives and to whatever he formerly liked best (p. 76; melancholia simplex)

A Text-Book of Psychiatry [35]

(The patient) is unable to take an interest in what goes on around him, and thinks of himself as a man apart, and that it would be better if he were dead (p. 133; simple retardation)

In others, instead of depression, there is a total loss of feeling - the patient complaining bitterly of the lack of emotion whatsoever, including a loss of affective response to those whom he formerly loved ( $\mathrm{p}$. 136; simple retardation)

No interest being taken in anything outside of the delusions, consciousness is befogged (p. 140; depressive stupor)

Melancholia: A Clinical Survey of Depressive States [36]

In a clinic such as that at Heidelberg, where most of the patients are peasants from the Palatinate, or Baden, one is amazed at the frequency with which depressive patients mention this failure to enjoy the sight of their fields, the sky and the trees and the flowers as one of the most distressing of their symptoms, a deprivation most keenly felt (p. 331; feeling of unreality, depersonalization)

Clinical Psychiatry [37] (He) takes little interest in topics that usually elicit an affective response. The complaint may be one of sudden and complete loss of interest and enjoyment in usual pursuits

With this there is a diminished capacity for normal affective response to sad as well as happy events The patient complains of and seems to be deeply upset by an awareness that he cannot feel pleasure or pain, that he has lost his ability to love his dear ones, his affection for his wife and children, that everything that aroused his emotion before leaves him indifferent and cold (p. 197-201; depression, affective psychoses)

\section{Anhedonia: The Behaviour}

In the DSM-III diagnostic criteria of MDD anhedonia was described as "loss of interest or pleasure in all or almost all usual activities and pastimes" [2]. A similar description is given in the current DSM-5 diagnostic criteria: "markedly diminished interest or pleasure in all, or almost all, activities most of the day, nearly every day (as indicated by either subjective account or observation)" [1]. In the text on diagnostic features this criterion is made more explicit: "Feeling less interested in hobbies, not caring anymore, not feeling any enjoyment in activities that were previously considered pleasurable, reduction from previous levels of sexual interest of desire. Family members may notice social withdrawal or neglect of pleasurable avocations." 
Psychiatric textbooks, predating DSM-III, offer a far more detailed picture of depressive states and anhedonic behaviour. Table 1 gives an overview of anhedonia as mentioned in a selected sample of psychiatric texts [3237]. A selection was made of influential English texts published at the end of the nineteenth and first half of the twentieth century, antedating DSM-III and belonging to one psychopathological "episteme" [15]. These texts have been influential due to both their content and authorship, with all authors being leading psychiatrists of their time. These texts were carefully checked for descriptions that could pertain to anhedonia.

\section{Anhedonia: The Concept}

Different concepts of anhedonia have been described, for example, Meehl's [38] low hedonic capacity as a predisposing factor for both schizophrenia and depression, and Klein's [12] impairment of appetitive and consummatory pleasure as a hallmark of endogenomorphic depression. More recent and popular concepts pertain to the pleasure cycle and positive affectivity. Both concepts partially overlap and offer a link between psychological categories (e.g., pleasure or anhedonia) and their neurobiological substrates. However, they differ in their origin and perspective. The pleasure cycle concept is grounded in the affective neurosciences and narrowly focused on reward. Part of its success has been the scientific strategy of dividing the concept of pleasure into the affective reaction (objective behavioural, physiological, and neural reactions) and its subjective affective experience [39]. The positive affectivity concept is grounded in a more general theory of affective psychology. Given their popular use (in which clinical anhedonia is often equated with deficits in reward processing or positive affectivity), a careful description of these concepts seems justified.

1. The pleasure cycle. The study of reward processing has found substantial evidence for distinct phases within a pleasure cycle, each phase having its own brain circuitry: an appetitive phase (dominated by wanting), a consummatory phase (dominated by liking), and a satiety phase (dominated by learning). Wanting is defined as the motivation for or the incentive salience of a reward, liking as the actual pleasure or hedonic impact of a reward, learning as associations, representations, and predictions about future rewards based on past experience. Wanting, liking, and learning constantly interact, wax and wane during the different phases of the pleasure cycle. They all have both con- scious and unconscious components $[18,19,40,41]$. Anhedonia is then defined as "the impaired ability to pursue, experience, and/or learn about pleasure, which is often, but not always accessible to conscious awareness" [19]. This model is further elaborated by Rizvi et al. $[42,43]$, who describe the reward process as initially building a stimulus-reward association, which then leads to interest/desire (wanting a reward), anticipation (state of readiness for a reward), motivation (initial energy expenditure to attain a reward), effort (sustained energy expenditure to attain reward), hedonic response (e.g., enjoyment of reward), and feedback integration (updating reward presence and values). In this model rewards can be primary/fundamental (e.g., food, sex, social interaction) or secondary/higher order (e.g., monetary, artistic, altruistic, and transcendental); their involved brain mechanisms are supposed to generally overlap and to be distinct from the mediation of other features of the same event (e.g., sensory, cognitive). The actual experience of pleasure is different from a mere sensation and/or a thought, it is an additional "hedonic gloss" generated by the pleasure networks of the human brain $[43,44]$. Although historically the liking part of anhedonia in depression has been emphasized, recent findings point at a greater importance of both wanting and learning: that is, a reduction in reward anticipation, the willingness to exert effort in order to get a reward, and the ability to modify behaviour as a function of reward [19, 45-47]. This concept of (an)hedonia is largely reflected in the positive valence systems of the Research Domain Criteria (NIMH): reward valuation (reward, delay, effort), reward responsiveness (reward anticipation, initial response to reward, reward satiation), and learning (probabilistic and reinforcement learning, reward prediction error, habit) [48].

2. Positive affectivity. In addition to anhedonia as a specific dysfunction of the pleasure cycle, anhedonia may also be described within more general, dimensional models of affect. Based on studies of the intercorrelations among emotional experiences (subjective reports of words, faces, and experiences) these models organize our affective space in 2 (or more) higher order dimensions (the circumplex models of affect): for example, valence and arousal [49], positive and negative affect (PA and NA) [16]. Affective states are then construed as linear combinations of these 2 dimensions. In these models a distinction can be made between "core affect" (object-free, flee-floating neurophysiological state - consciously accessible as a simple, 
non-reflective feeling) and emotional episodes. These latter are changes in core affect elicited by and attributed to an object. Emotional episodes are accompanied by instrumental action, physiological, and expressive changes (as part of the changes in core affect and as part of the instrumental action), perceptualcognitive appraisal of the object (for example, expectations for the future, relevance for one's goals, causal antecedents), and other conscious, subjective experiences. The subjective experience of a specific emotion (or emotional meta-experience; e.g., a person perceiving himself as being happy) finally results from a cognitive interpretation/categorisation of the neurophysiological changes that are elicited by the object: these changes being organised in relation to their object, behavioural responses, past experiences, and semantic knowledge [50,51]. The modelling of the affective space into PA and NA seems of particular interest for anhedonia in depression [52]. PA and NA pertain to the general and evolutionary adaptive systems of approach and withdrawal. PA represents the extent to which a person avows a zest for life, and NA the extent to which a person reports feeling upset or unpleasantly aroused [16]. PA and NA are not therefore opposites, but uncorrelated and independent dimensions. In particular, PA feelings (feelings of energy, vigour, enthusiasm, confidence) serve as a motivating source and affective reward of goal-directed behaviour [53]. Anhedonia may then be defined as low PA. Defined as such, anhedonia appears to be a relatively specific feature of depression: more specific than high NA [54].

\section{Anhedonia: A Psychopathological Perspective}

Anhedonia may be deconstructed according to different principles $[14,31,55]$.

1. Inherent in its current use is the difference between consummatory (lack of actual pleasure, experiential enjoying, liking) and appetitive (lack of interest, looking forward and wanting) anhedonia. Thereby, the form (in a Jaspersian tradition) of anhedonia is complex: phenomena pertaining to both feeling and affective states, and urge, drive, and will $[56,57]$.

2. A difference has to be made between anhedonic symptoms (patients' subjective complaints; for example, loss of interest and enjoyment) and signs (behaviour deemed pathological by a clinician; e.g., lack of positive emotions or mood observed/elicited during a psychiatric interview) $[58,59]$. Theoretically, anhedonic symptoms should be differentiated from an impaired ability to express (in words or behaviour) the feeling of pleasure, that is, a kind of "anhedonic alexithymia."

3. Anhedonia may be a trait or a state. A historical example of the former is low hedonic capacity as a risk factor for schizophrenia [38]. An example of the latter is anhedonia as defined in current DSM classifications of MDD.

4. Anhedonia may be pervasive or selective. Like pleasure, anhedonia may then be divided according to its object. Pleasures like food, sex, and social interaction are said to be fundamental (or primary, instinctual) the reward is inherent. They contrast with higher order (or secondary, non-instinctual) pleasures (like music, art, money, intellectual and altruistic activities) - the reward is not inherent and has to be learned [19, 43]. These rewards may belong to the past (remembered), present (actually experienced), or future (anticipated).

5. Although anhedonia suggests a categorical all-ornothing phenomenon, anhedonia (or hedonic functioning) has to be seen within a dimensional perspective.

6. Finally, anhedonia may exist on its own or may be part of a more general flattening of emotions and affect (e.g., general paralysis of feeling, blunted affect, derealisation).

\section{Discussion}

The history of anhedonia, as a word, is a clear-cut story. "Anhedonia" was invented by Ribot [26] to describe an affective state with disappearance of pleasure (physical and psychic). The appearance of "anhedonia" and its initial popularity $[28,29]$ coincided with a generally growing interest in affectivity as part of mental disorders in the second half of the nineteenth century $[15,60]$. From the start (and still present in current DSM classification of MDD), "anhedonia" was described as a compound feature or symptom complex. This was done most clearly by Myerson [29] - anhedonia as the disappearance of desire, satisfaction and the feeling of energy, and feelings of unreality.

Loss of interest or pleasure, as core symptoms of depression, are explicitly mentioned in all reviewed texts: only "anhedonia" was totally new, not the underlying phenomena. In contrast to DSM operational criteria, these texts offer a much more nuanced description of "anhedonia" as a symptom complex. Besides want of interest 
and enjoyment, other neighbouring symptoms are mentioned: for example, loss of vigour in the representation of the environment, loss of mental energy, loss of affective response (to sad as well as happy events), depersonalisation and derealisation, paralysis and total loss of feeling, painful feeling of having lost feeling. Not only symptoms but also their interconnectedness are explained, for example connectedness of lack of interest and pleasure with (mental) energy and derealisation, depersonalisation, painful feeling of having lost feeling. These descriptions could be seen as early attempts of what is now called the network approach to psychopathology [61-63]: mental disorders being understood as networks of interacting symptoms.

A popular concept (derived from the affective neuroscience of reward processing and the pleasure cycle) defines anhedonia as the impaired ability to pursue (wanting), experience (liking), and/or learn about pleasure, which is often, but not always, accessible to conscious awareness [19]. Like the historical descriptions of anhedonia this concept offers a kind of rationale for interrelated symptoms or an anhedonic symptom complex. From a psychopathological point of view some problems/shortcomings of this concept should be mentioned. First, "anhedonia" clearly cuts across the classic tripartite model of the mind. Anhedonic symptoms pertain to volition (e.g., apathy or diminished motivation; avolition or diminished ability to initiate and maintain goal directed behaviour; anergia or diminished perceived energy), fatigue (weariness or diminished ability following mental or physical activity), affect (lack of pleasure and enjoyment) and cognition, without clear boundaries [64, 65]. Second, the pleasure cycle (like a hedonic treadmill driven by ever changing concrete primary or secondary rewards) seems more suitable for understanding and describing (the lack of) positive emotions, and less suitable for describing (the lack of) positive mood or affect. For this latter purpose, the concept of positive affect seems more helpful $[51,52,54]$ with anhedonia being defined as low positive affect (including emotion, mood, and affective trait). Hedonic symptoms within the pleasure cycle are part of an emotional episode: a sudden change in affect, elicited by an object and characterized by diminished interest, energy, and pleasure. When present (or absent), these symptoms are at the foreground of our awareness but difficult to assess due to their short duration and limited pervasiveness in consciousness. Anhedonic mood/trait is longer lasting, more object-free, characterized by an overall diminished zest for life and feeling of energy, having more influence on other physi-

What We Talk about When We Talk about Anhedonia in Depression ological and psychological processes [66]. Although more at the background of our awareness, it is more easily assessed due to its longer duration and pervasiveness in consciousness. When interviewing a depressed patient, anhedonic signs will be looked for. For anhedonic symptoms the physician will have to rely on the verbal account of the patient; this will be less suitable for positive emotions (for which limited memory by nature), and more applicable for mood and trait.

This reviewing of anhedonia (word, behaviour, concept) underscores the complex and hybrid nature of mental symptoms. Anhedonic symptoms are a primary unit of analysis in the diagnosis and treatment of depression, but are clearly not natural kinds $[58,59]$. They result from a biological signal, a primordial (pre-conceptual, pre-linguistic) awareness of this signal and a formatting of this awareness through different configurators (cultural, social, familial, personal); finally, symptoms are expressed and constructed within a clinical and dialogical encounter. Concepts like the pleasure cycle and the affective circumplex may shed different lights on this black box of anhedonic symptom formation.

Finally, and from a more phenomenological point of view, severe and pervasive anhedonia in depression (as described in the aforementioned models) is more than a symptom or constellation of symptoms. It rather could be the primal manifestation or essential characteristic, an existential change in the sense of reality, of which anhedonic symptoms are representative [67-69]. Assessment of anhedonia as such could then lead to a better understanding of the depressed patient and (in the end) better outcome. This better understanding in general could be as (or even more) important than the different phases of the pleasure cycle as specific targets for biological or psychotherapeutic interventions [70].

\section{Conclusion}

In this narrative review we have given an overview of anhedonia in depressive states: word, behaviour, and concept. In the current form of diagnosis, treatment, and research of depression, we use anhedonia as a natural kind: signs and symptoms that can be elicited, detected or asked about, within the affective realm and to be differentiated from other signs/symptoms like apathy, avolition, or anergia. However, anhedonia appears to be far more complex with many interrelated and overlapping symptoms without clear boundaries. Descriptive psychopathology (of which the current DSM diag- 
nostic criteria are an often forgotten offspring) still follows the tradition of Karl Jaspers, that is, avoiding theoretical interpretation and the centrality of empathic understanding $[71,72]$. This contrasts with a growing knowledge of how symptoms are constructed and how they interconnect $[58,59,73]$. Concepts of anhedonia, as described above, are concrete neurobiological and psychological elaborations of this latter. They may add to a better explaining and understanding of the depressed patient, but are still in need of a corresponding psychopathological language.

\section{Acknowledgements}

We would like to thank David Richardson (Devon Partnership NHS Trust) for his language editing and proof reading of the text.

\section{Conflict of Interest Statement}

J.D.F. has been member of an advisory board of Janssen-Cilag NV. K.D. has been involved in advisory boards and speaker bureaus with Boehringer Ingelheim, Johnson \& Johnson, LivaNova, Lundbeck, and Servier. B.S. has received grants and was a consultant for Bristol-Myers Squibb, Janssen Pharmaceutica, Lundbeck, and Takeda.

\section{Funding Sources}

The authors received no external funding for this paper.

\section{Author Contributions}

J.D.F. wrote the draft manuscript, which was repeatedly revised and supplemented by all authors.

\section{References}

1 American Psychiatric Organization. Diagnostic and Statistical Manual of Mental Disorders. 5th ed. Arlington: American Psychiatric Organization; 2013.

2 American Psychiatric Organization. Diagnostic and Statistical Manual of Mental Disorders. 3rd ed. American Psychiatric Organization; 1980.

3 Spitzer RL, Endicott J, Robins E. Research diagnostic criteria: rationale and reliability. Arch Gen Psychiatry. 1978 Jun;35(6):773-82.

4 American Psychiatric Organization. Diagnostic and Statistical Manual of Mental Disorders. 2nd ed. Washington: American Psychiatric Organization; 1968.

5 American Psychiatric Organization. Diagnostic and Statistical Manual of Mental Disorders. 1st ed. Washington: American Psychiatric Organization; 1952.

6 Stone TT, Burris BC. Melancholia; clinical study of 50 selected cases. J Am Med Assoc. 1950 Jan;142(3):165-8.

7 Cassidy WL, Flanagan NB, Spellman M, Cohen ME. Clinical observations in manic-depressive disease; a quantitative study of one hundred manic-depressive patients and fifty medically sick controls. J Am Med Assoc. 1957 Aug;164(14):1535-46.

8 Feighner JP, Robins E, Guze SB, Woodruff RA Jr, Winokur G, Munoz R. Diagnostic criteria for use in psychiatric research. Arch Gen Psychiatry. 1972 Jan;26(1):57-63.

9 Kendler KS. The Phenomenology of Major Depression and the Representativeness and Nature of DSM Criteria. Am J Psychiatry. 2016 Aug;173(8):771-80.

10 Kendler KS. The genealogy of major depression: symptoms and signs of melancholia from 1880 to 1900 . Mol Psychiatry. 2017 Nov; 22(11):1539-53.
11 Klein D. Depression and Anhedonia. In: Clark DC, Fawcett J, editors. Anhedonia and Affect Deficit States. New York: PMA Publishing Corp.; 1987. pp. 1-14.

12 Klein DF. Endogenomorphic depression. A conceptual and terminological revision. Arch Gen Psychiatry. 1974 Oct;31(4):447-54.

13 Berrios GE, Olivares JM. The anhedonias: a conceptual history. Hist Psychiatry. 1995 Dec; 6(24 Pt 4):453-70.

14 Olivares JM, Berrios GE. The anhedonias: clinical and neurobiological aspects. Int J Psychiatry Clin Pract. 1998;2(3):157-71.

15 Berrios G. The History of Mental Symptoms. Cambridge: Cambridge University Press; 1996.

16 Watson D, Tellegen A. Toward a consensual structure of mood. Psychol Bull. 1985 Sep; 98(2):219-35.

17 Treadway MT, Zald DH. Reconsidering anhedonia in depression: lessons from translational neuroscience. Neurosci Biobehav Rev. 2011 Jan;35(3):537-55.

18 Kringelbach ML, Berridge KC. Towards a functional neuroanatomy of pleasure and happiness. Trends Cogn Sci. 2009 Nov; 13(11):479-87.

19 Rømer Thomsen K, Whybrow PC, Kringelbach ML. Reconceptualizing anhedonia: novel perspectives on balancing the pleasure networks in the human brain. Front Behav Neurosci. 2015 Mar;9:49.

20 Demyttenaere K, Donneau AF, Albert A, Ansseau M, Constant E, van Heeringen $\mathrm{K}$. What is important in being cured from depression? Discordance between physicians and patients (1). J Affect Disord. 2015 Mar;174:390-6.

21 Geschwind N, Nicolson NA, Peeters F, van Os J, Barge-Schaapveld D, Wichers M. Early improvement in positive rather than negative emotion predicts remission from depression after pharmacotherapy. Eur Neuropsychopharmacol. 2011 Mar;21(3):241-7.

22 Uher R, Perlis RH, Henigsberg N, Zobel A, Rietschel M, Mors O, et al. Depression symptom dimensions as predictors of antidepressant treatment outcome: replicable evidence for interest-activity symptoms. Psychol Med. 2012 May;42(5):967-80.

23 Zimmerman M, McGlinchey JB, Posternak MA, Friedman M, Attiullah N, Boerescu D. How should remission from depression be defined? The depressed patient's perspective. Am J Psychiatry. 2006 Jan;163(1):14850.

24 Simmons WK, Drevets WC. A "taste" of what is to come: reward sensitivity as a potential endophenotype for major depressive disorder. Biol Psychiatry. 2012 Oct;72(7):526-7.

25 Goldstein BL, Klein DN. A review of selected candidate endophenotypes for depression. Clin Psychol Rev. 2014 Jul;34(5):417-27.

26 Ribot T. La Psychologie des Sentiments. Paris: Ancienne Librairie Germer Baillière et Cie; 1896.

27 Dumas G. La tristesse et la Joie. Paris: Ancienne Librairie Germer Baillière et Cie; 1900.

28 James W. The Varieties of Religious Experience. New York: Longmans, Green, and Co; 1902.

29 Myerson A. Anhedonia. Am J Psychiatry. 1922 Jul;79(1):87-103.

30 Alexander L, Berkeley AW. The inert psychasthenic reaction (anhedonia) as differentiated from classic depression and its response to iproniazid. Ann N Y Acad Sci. 1959 Sep; 80(3):669-79.

31 Snaith P. Anhedonia: a neglected symptom of psychopathology. Psychol Med. 1993 Nov; 23(4):957-66. 
32 Clouston TS. Clinical lectures on mental diseases. 3rd ed. London: J\&A Churchill; 1892.

33 Bevan Lewis B. A text-book of mental diseases. 2nd ed. London: Charles Griffin and Company; 1899.

34 Kraepelin E. Manic-depressive insanity and paranoia. Edinburgh: E\&S Livingstone; 1921.

35 Henderson DK, Gillespie RD. A text-book of psychiatry. Edinburgh: Oxford University Press; 1927.

36 Lewis AJ. Melancholia: a clinical survey of depressive states. J Ment Sci. 1934 Apr;80(329): 277-378.

37 Mayer-Gross W, Slater ER. Clinical psychiatry. Baltimore: Williams and Wilkins Company; 1955.

38 Meehl PE. Schizotaxia, schizotypia, schizophrenia. Am Psychol. 1962;17(12):827-38.

39 Kringelbach ML, Berridge KC. The affective core of emotion: linking pleasure, subjective well-being, and optimal metastability in the brain. Emot Rev. 2017 Jul;9(3):191-9.

40 Berridge KC, Kringelbach ML. Affective neuroscience of pleasure: reward in humans and animals. Psychopharmacology. 2008 Aug; 199(3):457-80

41 Thomsen KR. Measuring anhedonia: impaired ability to pursue, experience, and learn about reward. Front Psychol. 2015 Sep;6: 1409.

42 Rizvi SJ, Quilty LC, Sproule BA, Cyriac A, Michael Bagby R, Kennedy SH. Development and validation of the Dimensional Anhedonia Rating Scale (DARS) in a community sample and individuals with major depression. Psychiatry Res. 2015 Sep;229(1-2):109-19.

43 Rizvi SJ, Pizzagalli DA, Sproule BA, Kennedy $\mathrm{SH}$. Assessing anhedonia in depression: potentials and pitfalls. Neurosci Biobehav Rev. 2016 Jun;65:21-35.

44 Kringelbach ML, Berridge KC. The functional neuroanatomy of pleasure and happiness. Discov Med. 2010 Jun;9(49):579-87.

45 Admon R, Pizzagalli DA. Dysfunctional reward processing in depression. Curr Opin Psychol. 2015 Aug;4:114-8.

46 Soskin DP, Holt DJ, Sacco GR, Fava M. Incentive salience: novel treatment strategies for major depression. CNS Spectr. 2013 Dec; 18(6):307-14.

47 Whitton AE, Treadway MT, Pizzagalli DA. Reward processing dysfunction in major depression, bipolar disorder and schizophrenia. Curr Opin Psychiatry. 2015 Jan;28(1):7-12.
48 Research Domain Criteria (RDoC) [Internet]. Available from: https://www.nimh.nih.gov/ research/research-funded-by-nimh/rdoc/index.shtml.

49 Russell JA. A circumplex model of affect. J Pers Soc Psychol. 1980 Dec;39(6):1161-78.

50 Russell JA. Core affect and the psychological construction of emotion. Psychol Rev. 2003 Jan;110(1):145-72.

51 Posner J, Russell JA, Peterson BS. The circumplex model of affect: an integrative approach to affective neuroscience, cognitive development, and psychopathology. Dev Psychopathol. 2005;17(3):715-34

52 Soskin DP, Carl JR, Alpert J, Fava M. Antidepressant effects on emotional temperament: toward a biobehavioral research paradigm for major depressive disorder. CNS Neurosci Ther. 2012 Jun;18(6):441-51.

53 Watson D, Wiese D, Vaidya J, Tellegen A. The two general activation systems of affect: structural evolutionary considerations, and psychobiological evidence. J Pers Soc Psychol. 1999 May;76(5):820-38.

54 Watson D, Naragon-Gainey K. On the specificity of positive emotional dysfunction in psychopathology: evidence from the mood and anxiety disorders and schizophrenia/ schizotypy. Clin Psychol Rev. 2010 Nov; 30(7):839-48

55 Demyttenaere K, Mortier P, Kiekens G, Bruffaerts R. Is there enough "interest in and pleasure in" the concept of depression? The development of the Leuven Affect and Pleasure Scale (LAPS). CNS Spectr. 2019 Apr;24(2): 265-74.

56 Jaspers K. General psychopathology. Voume 1. Baltimore: Johns Hopkins University Press; 1997.

57 Oyebode F. Sims' symptoms in the mind: an introduction to descriptive psychopathology. 4th ed. Amsterdam: Elsevier; 2008.

58 Marková IS, Berrios GE. Epistemology of mental symptoms. Psychopathology. 2009; 42(6):343-9.

59 Berrios G. Formation and meaning of mental symtoms: history and epistemology. Dialogues Phil Ment Neuro Sci. 2013;6(2):39-48.

60 Shorter E. What psychiatry left out of the DSM-5: historical mental disorders today. New York: Routledge; 2015

61 Bringmann LF, Vissers N, Wichers M, Geschwind N, Kuppens P, Peeters F, et al. A network approach to psychopathology: new insights into clinical longitudinal data. PLoS One. 2013 Apr;8(4):e60188.
62 Borsboom D, Cramer AO, Schmittmann VD, Epskamp S, Waldorp LJ. The small world of psychopathology. PLoS One. 2011;6(11): e27407.

63 Fried EI. Problematic assumptions have slowed down depression research: why symptoms, not syndromes are the way forward. Front Psychol. 2015 Mar;6:309.

64 Calabrese JR, Fava M, Garibaldi G, Grunze H, Krystal AD, Laughren T, et al. Methodological approaches and magnitude of the clinical unmet need associated with amotivation in mood disorders. J Affect Disord. 2014 Oct; 168:439-51.

65 Husain M, Roiser JP. Neuroscience of apathy and anhedonia: a transdiagnostic approach. Nat Rev Neurosci. 2018 Aug;19(8):470-84.

66 Rosenberg EL. Levels of analysis and the organization of affect. Rev Gen Psychol. 1998; 2(3):247-70.

67 Aho K. Affectivity and its disorders. In: Stanghellini G, Broome M, Raballo A, Fernandez AV, Fusar-Poli P, Rosfort R, editors. The Oxford Hanbook of Phenomenological Psychopathology. Oxford: Oxford Unversity Press; 2019.

68 Micali S. Hubertus tellenbach. In: Stanghellini G, Broome M, Raballo A, Fernandez AV, Fusar-Poli P, Rosfort R, editors. The Oxford Hanbook of Phenomenological Psychopathology. Oxford: Oxford University Press; 2019.

69 Ratcliffe M. Understanding existential changes in psychiatric illness: the indispensability of phenomenology. In: Ratcliffe M, Bortolotti L, editors. Psychiatry as Cognitive Neuroscience: Philosophical Perspectives. Oxford: Oxford University Press; 2013.

70 Winer ES, Jordan DG, Collins AC. Conceptualizing anhedonias and implications for depression treatments. Psychol Res Behav Manag. 2019 May;12:325-35.

71 Stanghellini G. The meanings of psychopathology. Curr Opin Psychiatry. 2009 Nov; 22(6):559-64.

72 Stanghellini G. A hermeneutic framework for psychopathology. Psychopathology. 2010; 43(5):319-26.

73 Kendler KS, Campbell J. Expanding the domain of the understandable in psychiatric illness: an updating of the Jasperian framework of explanation and understanding. Psychol Med. 2014 Jan;44(1):1-7.
What We Talk about When We Talk about Anhedonia in Depression
Psychopathology 2020;53:274-281 